\title{
ASCRIBING INTENTIONALITY
}

Gordon R. Foxall

Cardiff University

\begin{abstract}
Much of the commentary on my paper "Intentional behaviorism" (Foxall, 2007) fails to make contact with my central arguments about the use of intentional language in the explanation of behavior. Marr's (2008) remarks on my responses to that commentary (Foxall, 2008) also fail to address my original assertions. Both commentary and remarks tilt at windmills that were not in the landscape I described or hinted at in the solutions I proposed. I attempt here to map out my argument more clearly.

Key words: radical behaviorism, intentional psychology, philosophy of science, explanation
\end{abstract}

Behaviorism inveighs against resort to intentional terms to provide readymade but spurious explanations of observed behavior, an opportunistic practice in which ad hoc explicators are arbitrarily invented with the result that inquiry is brought to a premature end (Skinner, 1950,1963). Necessary as this admonition is in a social science that at times continues to adopt ungrounded trait theories (Bandura, 1986), intentional explanation is inevitable. Even radical behaviorism, which is founded on the principle that behavior is to be explained in nonintentional language, is incapable of providing an extensional account of such aspects of behavior as its continuity, or of the personal level of explanation, or of delimiting its interpretation of complex behavior (Foxall, 2004).

In the space available, I will refer only to behavioral continuity/discontinuity. Consider these examples. First, take a person whom we have observed drink alcohol heavily on a daily basis but who, we note, now drinks only on Friday evenings and confines himself to two drinks. As Rachlin (1995; see also Foxall, 2007) says, we explain his behavior by saying he has "decided" on this change. The use of intentional language appears to be inevitable if we are to account for this behavioral discontinuity. Second, consider a heavy user of the four brands A, $\mathrm{B}, \mathrm{C}$, and $\mathrm{D}$ that comprise her consideration set for a particular consumer nondurable, who now includes a new brand, E, in her repertoire. As is the case for many consumers in affluent societies, we cannot assume anything about her learning history except that she is a heavy user of the product category. It seems impossible to account fully for her inclusion of the new brand without referring to her beliefs and desires. Finally, there is the respondent in an operant experiment who maintains his behavior pattern even though the contingencies governing

AUTHOR'S NOTE: Please address correspondence to Gordon Foxall, Cardiff University, Aberconway Building, Colum Drive, Cardiff, CF10 3EU, UK; Email: foxall@cf.ac.uk. 
reinforcement of his behavior have changed. Again, there is little we can say about his learning history. It seems reasonable to assume some control of his overt behavior by his private verbal behavior, especially since we have no evidence of prior control of overt behavior via instructions. It does not seem that behavior such as this can be explained other than ascribing certain beliefs and desires to the experimental participant (Foxall \& Oliveira-Castro, 2009).

These three examples of behavioral continuity/discontinuity lie on a continuum of behavioral change which relates the sequence of observed behavior to changes in the attendant sequence of reinforcement. The behavior of the heavy user of alcohol which reflects some early signs of addiction (such as bingeing followed by remorse that is not sufficient to allay further bouts of heavy drinking) who adopts a more restrained pattern of moderated drinking cannot be explained in terms of the contingencies alone. The initial phase leads to aversive consequences which do not reduce the level of alcohol consumption; the subsequent behavior pattern is adopted before the novel consequences of restrained consumption have had time to exert an effect on choice. The abrupt change in the first molar pattern of behavior can be explained only in terms of the individual's having made a decision to try a different style of behavior. Such change is described as major or discontinuous.

The consumer who adopts a new brand also exhibits a change in her sequence of behavior, not by abandoning the existing pattern of choice but by supplementing and extending it. There is a change in behavior, but it amounts to no more than trying a new brand in a product category of which the consumer has much experience (i.e., a novel version of a familiar pattern of reinforcement). Most consumers of a product category purchase within a small consideration set of tried and tested brands; many, especially the heavier users of the product, try new brands that appear to contain the characteristics of the product class; some of those who try it incorporate the new brand into their future consideration set (Ehrenberg, 1988). Most consumers who select a new brand in this way or change to another in their existing consideration set choose one that contains a similar combination of functional and symbolic benefits (the pattern of reinforcement) as existing members of the set (Foxall, Oliveira-Castro, \& Schrezenmaier, 2004). The prediction of such behavior follows easily enough from consideration of the contingencies alone (at least for aggregates, not necessarily for individuals), but an explanation of the change itself requires consideration of the processes of comparison and recognition that must precede the change. How are the verbal stimuli (e.g., in ads) translated into the new pattern of consumer behavior via comparison with the characteristics of the brands already in the consumer's repertoire? Selective perception, beliefs, and desires must be used as part of the explanation of such behavior. It is not sufficient, therefore, to say that more continuous change of this sort, even though it may be readily related to the contingencies, is "explained" by its embodiment of stimulus or reinforcer discrimination and generalization. Use of such terminology merely redescribes the observed pattern of choice. 


\section{ASCRIBING INTENTIONALITY}

Finally, the behavior of the experimental subject which exhibits rigidity in the face of changing contingencies is an example of behavioral continuity that cannot be explained in terms of the contingencies themselves. Why is human behavior so insensitive to changes in contingencies when this is not true of nonhumans? The person presumably has not perceived the change in contingencies and is operating according to a self-generated rule reached in decision making prior to the contingency change. The behavior of persons in this situation often comes to conform to the contingencies after time. How does this change in perception occur? Is there further decision making?

In advocating that intentional terminology must be employed in the explanation of these behavior patterns, I am not making any assumptions about the ontology of beliefs, desires, or decision-making. I note, however, that we are forced to use intentional language faute de mieux and that radical behaviorists often do just that. But if we do so, we must be clear that beliefs and desires are not causal; they cannot enter into an experimental analysis. Our only reason for using them must be that the observed behavior can be fully explained only by ascribing them. Let us look at the nature of the changes in behavior in greater detail.

Radical behaviorism remains, nonetheless, a natural starting point for an investigation of why intentionality is required in behavioral explanation and how it may be legitimately ascribed. Based on the contextual stance (Foxall, 1999), which portrays behavior as determined by the individual's learning history and current behavior setting, its initial adoption is necessary in order to ascertain what may be uniquely achieved on the basis of an extensional model and the point at which intentionality must be brought in to make further explanation possible. This diminishes the danger of incorporating intentional terms unnecessarily and allows their particular contribution to explanation to be gauged more precisely. At what juncture is non-extensional language required to account for some aspects of behavior, such as its continuity? What are the goals to which intentional language must be directed? And what is the minimal content that must be ascribed in order to provide the desired explanations?

Having determined that intentional terms must be incorporated into an extensional explanation of behavior, we are still faced with deciding how intentionality can be ascribed logically and parsimoniously in such an endeavor. Dennett's (1969) proposal that intentional content may be added based on the identification of evolutionarily-consistent afferent-efferent neuronal links in order to predict behavior must be supplemented with an account of how behavioral selection through operant contingencies contributes to neuronal plasticity, and it must, therefore, be considered in the process of content ascription. The behavioral route to content ascription is strengthened by recognition that even extreme behaviors such as addiction may be "voluntary," falling under the causal influence of environmental consequences, rather than "involuntary" in the sense of being biologically determined (Heyman, 2009). The tandem identification of appropriate afferent-efferent links relating to molar patterns of operant choice provides a rationale for the legitimate ascription of intentionality, a procedure known as intentional behaviorism. 
Intentional behaviorism runs in parallel with Dennett's Intentional Systems Theory (IST), a competence theory populated by abstracta, constructs that are more precisely defined than those described in the same words by intentional folk psychology. Abstracta lack the detailed precision that would allow them to enter, as illata, into testable psychological theories. The prediction of behavior based on neural ascription of intentionality gives way in IST to the prediction of intentional systems, those whose behavior is predictable if they are accorded the beliefs and desires they should hold by dint of their experience and present circumstance. Dennett has adopted the intentional stance. By contrast, intentional behaviorism is concerned with the explanation of behavior through the ascription of content which accounts for behavioral continuity and the personal level, and which permits delimitation of behavioral interpretation. It thereby retains, but supplements, Dennett's original (1969) criterion, to which we may refer as that of "neurallyascribed intentionality."

Intentional behaviorism is a linguistically based approach to explanation. Understanding the essential nature of radical behaviorism as an attempt to confine the explanation of behavior to extensional terminology, it is concerned with establishing criteria for the use of intentional terms when they become necessary. Intentionality itself is viewed within it as an entirely linguistic matter and it makes no ontological assumptions about its nature, extent, or incidence. Science is a matter of using language in a particular way; radical behaviorism strives to do so without recourse to intentional idioms, but it is ultimately unable to achieve this. In other words, radical behaviorism is extensional. What this means is that it is defined by the axiom that behavior is to be explained in extensional language. Behavior has been explained, according to this paradigm, when the environmental events that allow the behavior to be predicted and controlled have been identified. The definitions of the terms required to describe the relationships among the initial stimulus setting (discriminative stimuli and motivating operations), the response, and the consequential stimuli that determine the rate of future behavioral emission are all formulated in language that avoids intentionality. To the extent that behavior proves predictable from and subject to influence on the basis of the manipulation of environmental variables, this extensional position is consistent with the view that science is concerned only with the prediction and control of its subject matter.

It follows that to use intentional language is to use intentional explanation. Extensional explanation depends on the exclusive use of extensional language. To the extent that we had to use intentional language, not as a façon de parler but in order to explain aspects of behavior, we would be necessarily employing intentional explanation. Behavior analysts $d o$ use intentional terminology in order to account for certain aspects of behavior, as I illustrated in "Intentional Behaviorism Revisited" (Foxall, 2008; see also Foxall, 2004). It follows also that the use of intentional idioms is entirely a linguistic response to the need to describe a subject matter. It has no bearing on the causation of behavior, nor on the ontology with which we deal; there is no implication that we are using an internal route to explanation, nor that people really have beliefs and desires that influence 


\section{ASCRIBING INTENTIONALITY}

their behavior. Above all, it carries no imputation of agency. Its implications are solely for the way in which a subject matter is verbally described. The level of explanation at which intentionality is ascribed is also central to understanding the role of this kind of explanation. Beliefs and desires are ascribed, by the investigator, at the personal level, not-contra Dennett (1987); cf. Bennett \& Hacker (2003) - at the sub-personal level of neurons and brains. This is in accord with Skinner's (1974) ascription of private events at the level of the whole organism and his argument that whatever believing is, it is a behavior (hence a property of the whole organism), and with Rachlin's (1994) ascription of mentality in the form of patterns of overt behavior. But unlike their approaches, it does not construe intentionality ontologically; rather, it is a methodological consideration that arises from the ways in which scientists must, and do, describe certain aspects of their subject matter.

Intentional behaviorism cannot be a final resting place for the philosophy of psychology any more than IST is. The depiction of its constructs as place-holders should not be a source of triumphalism by radical behaviorists any more than the insistence of Skinner and others that physiology will one day provide a more comprehensive answer to the problem of behavioral continuity than radical behaviorism can currently do alone, itself a place holding statement, should give rise to ridicule (rather than critical assessment). Place-holders are essential components of scientific advance (e.g., Ross, 2005; Ladyman \& Ross, 2008). Moreover, the constructs which compose the intentional behaviorism approach have explanatory value in themselves, unavailable in strictly extensional behavioral science though essential to its completion of its mission to explicate behavior-else why do radical behaviorists employ them so frequently?

\section{References}

Bandura, A. (1986). Social foundations of thought and action. Englewood Cliffs, NJ: Prentice Hall.

Bennett, M. R., \& Hacker, P. M. S. (2003). Philosophical foundations of neuroscience. Oxford: Blackwell.

Dennett, D. C. (1969). Content and consciousness. London: Routledge \& Kegan Paul.

Dennett, D. C. (1987). The intentional stance. Cambridge, MA: MIT Press.

Ehrenberg, A. S. C. (1988). Repeat buying. New York: Oxford University Press.

Foxall, G. R. (1999). The contextual stance. Philosophical Psychology, 34, 768-779.

Foxall, G. R. (2004). Context and cognition: The interpretation of complex behavior. Reno, NV: Context Press.

Foxall, G. R. (2007). Explaining consumer choice: Coming to terms with intentionality. Behavioural Processes, 75, 129-145.

Foxall, G. R. (2008). Intentional behaviorism revisited. Behavior and Philosophy, 36, 113156.

Foxall, G. R., \& Oliveira-Castro, J. M. (2009). Intentional consequences of self-instruction. Behavior and Philosophy, 37, 87-104. 


\section{FOXALL}

Foxall, G. R., Oliveira-Castro, J. M., \& Schrezenmaier, T. C. (2004). The behavioral economics of consumer brand choice: Patterns of reinforcement and utility maximization. Behavioural Processes, 65, 235-260.

Heyman, G. (2009). Addiction: A disorder of choice. Cambridge, MA: Harvard University Press.

Ladyman, J., \& Ross, D., with Spurrett, D., \& Collier, J. (2008). Everything must go: Metaphysics naturalized. Oxford: Oxford University Press.

Marr, M. J. (2008). The abdication of belief: A comment on Foxall's replies to his critics. Behavior and Philosophy, 36, 157-168.

Rachlin, H. (1994). Behavior and mind. Oxford: Oxford University Press.

Rachlin, H. (1995). Self control: Beyond commitment. Behavioral and Brain Sciences, 18, 109-159.

Ross, D. (2005). Economic theory and cognitive science: Microexplanation. Cambridge, MA: MIT Press.

Skinner, B. F. (1950). Are theories of learning necessary? Psychological Review, 57, 193216.

Skinner, B. F. (1963). Behaviorism at fifty, Science, 140 (May 31), 951-959.

Skinner, B. F. (1974). About behaviorism. New York: Knopf. 